\title{
La identidad de género como derecho humano. Análisis del tránsito de un concepto en los discursos del Estado de la ciudad de Buenos Aires (período 2003-2010) ${ }^{1}$
}

\author{
Gender identity as a human right. Analysis of the transit of a concept \\ in the speeches of the State of the City of Buenos Aires (period \\ 2003-2010)
}

Anahí Farji Neer

\begin{abstract}
Resumen
El trabajo se propone analizar las formas mediante las cuales el Estado argentino regula las corporalidades que desafían el binarismo genérico. A partir del año 2003 surgieron una serie de regulaciones orientadas bajo el ideario del respeto a la identidad de género de travestis, transexuales y transgénero como un derecho humano. Interesa analizar los factores que hicieron posible dicho cambio regulativo, así como los modos en los que en dichos posicionamientos estatales son definidos el travestismo, la transexualidad y la transgeneridad y el concepto de identidad de género. Guía el presente trabajo la hipótesis de que nuevas fronteras de lo humano son instituidas bajo la noción de derecho humano a la identidad de género. Atento a dichos planteos, se analizan tres documentos oficiales a fin de abordar críticamente los sentidos presentes en los mismos.

El enfoque epistemológico del trabajo se basa en el método arqueológico desarrollado por Michel Foucault, particularmente en lo que respecta a su modo de entender los documentos como componentes de entramados discursivos históricamente constituidos. La estrategia metodológica central es el análisis de fuentes secundarias de datos: documentos textuales oficiales abordados bajo la técnica del análisis de contenido cualitativo.
\end{abstract}

Palabras clave: travestismo - transexualidad - transgeneridad - tecnologías de género - derechos humanos.

\begin{abstract}
This paper analyzes how the State regulates bodies that challenge binary gender rules. Since 2003, several regulations regarding the respect for trans gender identities emerged as part of a broader 'Human Rights' ideology in Argentina.

The factors that made this possible, and the ways in which the concepts of transvestism, transsexualism, transgenderism and gender identity are defined in those regulations are at the core of this article. This study is guided by the hypothesis that new human frontiers are instituted
\end{abstract}


under the notion of human rights related to gender identity. Thus, three official documents are analyzed to address the senses present therein.

The epistemological approach is based on Michel Foucault's archeology, particularly in regard to his understanding of the document's value. The central methodological strategy is the analysis of secondary data sources: official documents addressed using the content analysis's technique.

Key words: travestism - transexualism - transgender - technologies of gender - human rights.

\section{INTRODUCCIÓN}

El presente trabajo es parte de una investigación en curso sobre las formas en las que el Estado argentino lee y regula las corporalidades que desafían el binarismo genérico desde mediados del siglo XX hasta la actualidad. La misma se encuentra guiada por una estrategia de análisis documental, mediante el método de análisis de contenido cualitativo. A partir del relevamiento documental realizado se identificó una serie de regulaciones en torno a aquellas personas identificadas como travestis, transexuales y transgénero, cuyos contenidos han ido variando con el correr del tiempo. Teniendo en cuenta que las condiciones materiales de vida de travestis, transexuales y transgéneros no pueden ser escindidas de cierto tipo de predicados positivos o negativos atribuidos a las personas en función de su género o sexualidad, cabe realizar un abordaje que dé cuenta del contenido de dichas representaciones. En el presente trabajo se considerarán las prácticas y discursos del Estado como componentes fundamentales de las tecnologías que construyen los géneros, sus demarcaciones y patrones de inteligibilidad. Asimismo, se problematizarán los mecanismos con los cuales en dicho ámbito se (re)definen las fronteras de lo humano.

A fin de aclarar conceptualmente los términos utilizados, a lo largo de este trabajo se entenderá el travestismo, la transexualidad y la transgeneridad como posiciones de sujeto ${ }^{2}$ que se configuran a partir de una desviación de las normas binarias del género dominantes por medio de la adopción de una serie diacríticos asociados a un género distinto al socialmente asignado. Son posiciones de sujeto ininteligibles según el esquema binario de género, ya que siguiendo a Judith Butler, los géneros inteligibles son "aquellos que en algún sentido instituyen y mantienen relaciones de coherencia, continuidad entre sexo, género, práctica sexual y deseo" (Butler, 2001a: 50). Al mismo tiempo, se encuentran estrechamente vinculadas a dispositivos médicos de disciplinamiento y control, siendo estos los que durante mucho tiempo otorgaron a los propios sujetos las únicas categorías de nominación disponibles. El término travestismo surgió en Europa Occidental a fines del siglo XIX y principios del siglo XX en el momento del pasaje del control de las sexualidades consideradas como desviadas

En el sentido que lo entienden Ernesto Laclau y Chantal Mouffe (2004): "Siempre que en este texto utilicemos la categoría de sujeto, lo haremos en el sentido de 'posiciones de sujeto' en el interior de una estructura discursiva. Por lo tanto, los sujetos no pueden ser el origen de las relaciones sociales, ni siquiera en el sentido limitado de estar dotados de facultades que posibiliten una experiencia, ya que toda 'experiencia' depende de condiciones discursivas de posibilidad precisas" (2004: 156). 
del ámbito punitivo al ámbito médico descrito por Foucault en Historia de la sexualidad (1990). Fue desarrollada por psiquiatras y médicos europeos cuyos exponentes más reconocidos fueron Richard von Krafft Ebing, Henry Havelock Ellis y Magnus Hirschfeld. En el desarrollo del concepto elaborado por los distintos autores se fue pasando de un modo de entender al travestismo como un grado particular de desviación sexual (o la tendencia a la búsqueda de estímulos eróticos inadecuados) a utilizarlo para referirse a personas que al utilizar vestimenta considerada del sexo opuesto configuran una forma particular de subjetividad (King, 1998; Leite, 2008). Por su parte, la categoría transexual comenzó a circular en el ámbito clínico-médico a mitad de la década de 1950 con posterioridad a la realización de las primeras intervenciones quirúrgicas de reasignación genital y al desarrollo de la endocrinología. En 1953, Harry Benjamin, endocrinólogo alemán, acuñó el término transexual y la categoría diagnóstica de transexualismo para referirse a individuos que pertenecen físicamente a un sexo, se sienten psicológicamente del sexo contrario y desean alterar sus rasgos físicos quirúrgicamente. Benjamin concebía la cirugía de cambio de sexo como única alternativa terapéutica posible, descartando la efectividad de cualquier tratamiento psicoterapéutico (Billings y Urban, 1998; Bento, 2006). Luego, la primera utilización del término transgenderist vino de la mano de Virginia Prince en la década de 1970. Esta activista estadounidense formuló el término para referirse a aquellas personas que, al igual que ella, viven de forma íntegra en un género distinto al asignado al nacer sin tener el deseo de modificar su genitalidad quirúrgicamente. De acuerdo con dicha categoría, Prince se proponía visibilizar experiencias distintas a la transexualidad quirúrgica y discutir con las categorías médicas del transexualismo y el travestismo. El término transgénero fue ganando popularidad en el ámbito activista a partir de la década de 1990 de la mano del activismo y la teoría queer (Valentine, 2007).

Del análisis de la producción regulativa local, hasta el año 2003 fueron identificados dos patrones regulativos (Farji Neer, 2012). Por un lado, la sanción del travestismo mediante los edictos policiales vigentes en la ciudad de Buenos Aires a partir del año 1944. Estos penalizaban el hecho de "vestir con ropas del sexo opuesto", equiparando el travestismo a la criminalidad y entendiéndolo como un peligro social que debía controlarse. Por otro, se ha cifrado la existencia de personas cuyos deseos y expresiones de género desafían el binarismo genérico en tanto sujetos enfermos. De acuerdo con este guión, al Estado le había asignado el deber de protegerlos, arrogándose la potestad de evaluar la conveniencia de sus deseos, tanto para sí como para el resto de la sociedad. Sobre los jueces recayó entonces el poder de arbitrar en torno a la posibilidad de intervenir sus cuerpos quirúrgicamente y a ser reconocidas legalmente en un género distinto al que les fuera asignado al nacer. En dicho marco, el discurso médico psiquiátrico por medio del diagnóstico de transexualismo y trastorno de la identidad de género, había sido invocado como único discurso de verdad y prisma por el cual leer y comprender dichas formas de vida ${ }^{3}$.

3 Hasta la reciente sanción de la Ley de Identidad de Género, en lo que refiere a la posibilidad de alterar el nombre propio se encontraba vigente la Ley $N^{\circ}$ 18.248/68 (Ley del Nombre). Esta establecía que a fin de modificar el nombre asentado en la partida de nacimiento debía probarse frente a un juez la existencia de un "justo motivo". 
A partir del año 2003 comenzaron a surgir regulaciones orientadas bajo el ideario de la no discriminación y el respeto a las minorías. Dicho proceso fue profundizándose y permitió que se instale el respeto a la identidad de género y los deseos de travestis, transexuales y transgéneros como un derecho humano a ser garantizado por el Estado. Estas son las nociones que se ubican como fundamento de la recientemente aprobada Ley de Identidad de Género ${ }^{4}$

Sobre la base del relevamiento realizado, se hallaron una serie de documentos oficiales producidos entre los años 2003 y 2011 por distintas instancias del Estado argentino, en cuyos contenidos se encuentran presentes dichas ideas. Cabe entonces preguntarse por la génesis de estas formas regulativas, así como por los sentidos de dicho cambio discursivo iniciado en el año 2003 y vigente hasta el momento. En este sentido, surgen los siguientes interrogantes: ¿Qué hizo posible dicho cambio regulativo-discursivo? ¿De qué modos se define el travestismo, la transexualidad y la transgeneridad en estos posicionamientos estatales? ¿Cómo es entendida allí la identidad de género? ¿Qué nuevas fronteras de lo humano se instituyen bajo la noción de derecho humano a la identidad de género?

A la luz de estos interrogantes se han seleccionado tres documentos producidos en el ámbito de la ciudad de Buenos Aires. Dicho recorte no resulta arbitrario, ya que esta jurisdicción es predominante en lo que atañe a la producción de este tipo de regulaciones. A fin de arribar a un análisis representativo de las formas específicas de regulación de los tres poderes del Estado, cada uno de los documentos seleccionados ha sido producido por uno de ellos. A saber:

1. La Resolución producida por la Secretaría de Educación del Gobierno de la Ciudad de Buenos Aires en el año 2003 en la que se recomienda que las instituciones educativas garanticen el respeto por la identidad de género de las personas pertenecientes a minorías sexuales (Resolución 122/03 B. 0. 1642/03).

2. La Ley sancionada por la Legislatura de la Ciudad de Buenos Aires que en el año 2009 establece "asegurar que travestis y transexuales sean nombradas y nombrados respetando su identidad de género" en toda dependencia pública de la Ciudad de Buenos Aires (Ley No3.062/2009).

Por otro lado la Ley N 17.132/67 de Ejercicio de la Medicina prohibía el "cambio de sexo", salvo que se obtuviese una orden judicial que lo autorizara. Por lo tanto, en los requerimientos de rectificación de sexo y/o nombre en el DNI o bien para acceder a una cirugía de reasignación genital, la vía judicial resultaba ineludible.

$4 \quad$ La Ley de Identidad de Género (Ley No 26.743), aprobada el 9 de mayo de 2012, permite que los cambios registrales de sexo y nombre sean realizados por un trámite administrativo sin intervención judicial. Asimismo, dictamina que los tratamientos hormonales y quirúrgicos sean realizados por los efectores del sistema público de salud -público o privado- sin requerir una autorización judicial. Esta ley afirma la despatologización de las identidades trans ya que deja de considerarlas como personas enfermas. Hace efectiva también la desjudicialización de sus derechos dado que el cambio de nombre y sexo registral es vehiculizado mediante un trámite administrativo expeditivo ante el registro civil. Al mismo tiempo, tiene por objetivo promover su desestigmatización, incorporando la noción de no discriminación conforme los Principios de Yogyakarta. Por último, y como resultante de las anteriores, la ley avanza en la descriminalización las identidades trans. 
3. Un fallo producido por un Juzgado en lo Contencioso Administrativo de la Ciudad de Buenos Aires en el año 2010 en el que se autoriza el cambio de nombre y sexo registral de una persona que habiendo sido registrada al momento de nacer como perteneciente al sexo masculino desea ser reconocida legalmente como femenina.

Guía el presente trabajo la idea de que la disputa por la ampliación de los límites de inteligibilidad de los cuerpos y las identidades se da en el plano de la representación, del discurso y de la nominación. Por ello, adquiere relevancia particular analizar la transformación de los discursos estatales de los últimos años, debido a que allí se cristalizan sentidos asociados a las sexualidades y corporalidades no normativas y es posible disputar la frontera culturalmente establecida entre las sexualidades legítimas y las ilegítimas (Rubin, 1989). En este sentido, el objetivo del presente trabajo es el de dar cuenta de los sentidos emergentes en torno al travestismo, la transexualidad y la transgeneridad cristalizados en documentos estatales, así como las nuevas formas regulativas que dichos sentidos habilitan. El enfoque epistemológico del trabajo se basa en el método arqueológico desarrollado por Michel Foucault, particularmente en su forma de entender los discursos no "como conjuntos de signos (...) sino como prácticas que forman sistemáticamente los objetos de que hablan" (Foucault, 1997: 81). De este autor se retoma también su concepción del documento como resultado de complejos entramados discursivos históricamente configurados.

En las primeras secciones del artículo se aborda el carácter discursivo de las regulaciones estatales desde una triple perspectiva: sus reglas de formación interna y externa, su carácter performativo y su forma de imbricación con el orden genérico y sexual. Luego, teniendo en cuenta estos tres factores se analizan las reglas de formación de los discursos de cada uno de los tres poderes del Estado. Posteriormente, se profundiza en las condiciones sociales de emergencia del guión regulativo del derecho humano a la identidad de género, dando cuenta del proceso de consolidación de las organizaciones sexo-políticas locales en general y de las organizaciones de travestis, transexuales y transgéneros en particular. Por último, se analizan los sentidos que cristalizan en los documentos oficiales seleccionados en los que se concibe el respeto a la identidad de género y los deseos de travestis, transexuales y transgéneros como un derecho humano.

\section{LA OPERATIVIDAD SOCIAL DEL DISCURSO JURÍDICO: SU CARÁCTER PERFORMATIVO}

A lo largo del trabajo se entenderá al Estado como un campo no homogéneo, por el contrario, atravesado por distintos vectores de poder en su interior. A su vez, se considera que sus divisiones institucionales en poderes legislativo, ejecutivo y judicial, así como en sus instancias nacional y provincial, hacen plausible la resolución particular y con cierta autonomía, de los asuntos de interés público planteados en cada una de ellas. La Constitución de la República Argentina establece la división en tres poderes: ejecutivo, legislativo y judicial. El sistema de gobierno es representativo, republicano y federal. De este modo, las veintitrés provincias pueden expedir sus 
propias normas dentro del marco establecido por la Constitución. Cada una de las provincias y la ciudad de Buenos Aires posee su Constitución y están facultadas a crear instituciones locales, así como a elegir sus gobernadores, legislaturas, códigos procesales y a establecer su propia administración de justicia. El modo en que cada instancia resuelve las problemáticas públicas se plasma en documentos oficiales textuales bajo la forma de leyes, resoluciones, disposiciones, fallos. Allí se explicitan las formas en la que dichas instancias entienden y resuelven los problemas concebidos como públicos, sobre la base de las lógicas regulativas propias del campo estatal y apelando a argumentos y esquemas conceptuales provenientes tanto de marcos jurídico-legales como de otros campos discursivos. Cada una de sus instancias jurídico-burocráticas representa un campo de disputas y negociaciones en torno a dichos sentidos.

En principio, es posible afirmar que el discurso jurídico o estatal circula mediante normas, reglamentos, decretos, fallos, edictos y sentencias, con la función de establecer lo permitido y lo prohibido formalmente en una sociedad. Es un tipo de discurso que al tiempo que prescribe, describe, dice algo sobre cómo debería ser el mundo y cómo es. Su pretensión de ser una descripción realista del mundo es una de las características que asume este tipo particular de discurso (Entelman, 1982). El sentido y la validez del mismo no están dados exclusivamente por la lógica que encadena sus enunciados, sino también, y fundamentalmente, por la lógica de las prácticas en las que se inscribe. Su operatividad está dada por su inscripción estatal, siendo esta la fuente de su autoridad. Su poder performativo -en el sentido de configurar sujetos y realidades jurídicas por medio del propio acto enunciativo (Austin, 1988)- también proviene del rol que ocupa la institución estatal en nuestras sociedades. De este modo, resulta pertinente concebir a la institución estatal como una de las que "conforman el aparato en el que se condensa el poder y los recursos de la dominación política" (Oszlak, 1978: 8), obteniendo su legitimidad y poder productivo de dicho orden de dominación institucional. Por ello se encuentra también investido de los ropajes del discurso justo y de verdad. No obstante, no obtiene su legitimidad exclusivamente del poder institucional, sino también del orden cultural que lo sustenta (Entelman, 1982).

Discurso jurídico y orden social se retroalimentan, ya que aquel opera como dispositivo de legitimación y sostén del reparto desigual del poder en la sociedad, ofreciendo los mecanismos de obediencia y control social necesarios para la reproducción de un orden jerárquico y desigualmente organizado. Enrique Marí (1994) agrega que para que sea operativo, el discurso del orden debe tener la capacidad de interpelar la emotividad de los sujetos, la movilización de creencias y sentimientos. La emotividad que este discurso invoca obedece al hecho de que al nombrar y especificar a los individuos, los constituye como sujetos que se hacen inteligibles por las categorías que este ofrece. En este mismo sentido, Judith Butler establece que "el sujeto se forma a través de la búsqueda apasionada del reconocimiento amonestador del Estado" (2001b: 143). Por todo ello, resulta de interés atender a la forma en la que este discurso se imbrica con el orden normativo de los géneros. 


\section{TECNOLOGÍAS DE GÉNERO / TECNOLOGÍAS DE LO HUMANO}

Siguiendo a Teresa de Lauretis, el género "es el producto de variadas tecnologías sexuales (...) y de discursos institucionalizados, de epistemologías y de prácticas críticas, tanto como de la vida cotidiana" (De Lauretis, 1998: 8). En este sentido, es dable considerar que las prácticas y discursos del Estado son una de las tecnologías que construyen los géneros, sus demarcaciones y patrones de inteligibilidad. Una multiplicidad de autoras ya se ha ocupado de señalar que el discurso jurídico opera sobre la base de una idea pretendidamente abstracta de ciudadano, equiparándolo a un sujeto heterosexual masculino (Maffía, 2001; Moreno, 2002; Pateman, 1995). Por ello es dable afirmar que este promueve una idea universal de lo humano a imagen y semejanza de dicho modelo y que naturaliza un concepto particular de sexualidad haciéndolo inteligible exclusivamente en los términos de la linealidad sexo-género-deseo. Entendiendo estos conceptos en términos binarios y dicotómicos, la noción de "sexo" referiría a la existencia de cuerpos sexuados en tanto machos o hembras. Luego, el "género" referiría al hecho de adscribir a la identidad femenina o masculina. Por último, la idea de "deseo" u "orientación sexual" se establecería teniendo en cuenta las características sexo-genéricas de las personas ubicadas como objeto de amor y/o placer, las que se espera que sean del sexo-género opuesto. El discurso jurídico opera entonces como un dispositivo que produce sujetos generizados a la luz de dicha idea. Resulta de interés indagar cómo se articula el discurso jurídico con las demandas de las personas identificadas como travestis, transexuales y/o transgéneros, debido a que en dichas experiencias la linealidad y binariedad queda subvertida por la adopción de una identidad genérica que desafía lo dictaminado por ese esquema.

Según Judith Butler (2006b), existe una noción normativa de lo que debe ser un cuerpo humano impuesta por el mismo discurso jurídico. Fuera de dicha normatividad, basada en aspectos tanto sexuales y genéricos como raciales, existen vidas que no se encuentran protegidas por el derecho por no adecuarse a lo que cuenta como una vida que valga la pena. Toda experiencia que queda por fuera de este esquema pasa a ser un fenómeno particular y atípico, generando tensiones entre lo pretendidamente universal y lo particular, lo público y lo privado, binomios que son impuestos por el mismo discurso. No obstante, tomando a Rita Segato (2003) es posible afirmar que "la ley también puede impulsar, informar, sensibilizar ese sentimiento ético y transformar la moral que sustenta las costumbres y el esquema jerárquico en la sociedad" (2003: 15). A partir de esta idea cabe considerar al discurso jurídico como un ámbito en el que es posible negociar la definición de la frontera culturalmente establecida entre los cuerpos legítimos y los ilegítimos (Rubin, 1989), así como los límites de aquello que puede definirse culturalmente como humano.

\section{LA DIVISIÓN DE PODERES Y SUS REGLAS DE PRODUCCIÓN DISCURSIVA}

A fin de analizar los documentos que hemos seleccionado, resulta de importancia tener en cuenta las reglas de producción discursiva vigentes al interior de cada uno de los tres poderes. Para ello describiremos brevemente no solo las funciones 
y potestades formales de cada uno de estos, sino también sus dinámicas de funcionamiento real.

En lo que refiere a aquellos documentos producidos por el poder ejecutivo, suele referirse a los mismos en términos de actos administrativos. Según la normativa de la ciudad de Buenos Aires, la función administrativa es realizada principalmente por el Poder Ejecutivo así como por "Ios Ministros y demás funcionarios del Poder Ejecutivo y los titulares de los órganos directivos de entes descentralizados (que) podrán dirigir o impulsar la acción de sus inferiores jerárquico mediante órdenes, instrucciones, circulares y reglamentos internos" (Dec. N ${ }^{\circ}$ 1.510/97). En este sentido, los actos administrativos se orientan a regular asuntos que pueden referir tanto a situaciones de ciudadanos/ as particulares, de interés general de la población, o bien a la organización interna del propio ámbito estatal. A fin de que dichos actos sean reconocidos como válidos por la propia administración, se establecen una serie de requisitos que deben cumplir ${ }^{5}$. Cabe considerar que los actos administrativos gozan de una presunción de legitimidad específica por la propia autoridad pública de la que emanan.

Respecto de las regulaciones producidas por el poder legislativo, acorde a la Constitución Nacional, las veintitrés provincias del país conservan poder y autoridad no delegada a la Nación, motivo por el cual tienen potestad para establecer sus propias leyes. Estas son sancionadas por un cuerpo de legisladores elegidos por voto directo y deben adecuarse a la Constitución Nacional, así como a los tratados de Derechos Humanos de rango constitucional. Las leyes son fruto de un debate público basado en mecanismos pronunciadamente pautados y ritualizados (Dollar, 2007; Hiller, 2011). En dicho mecanismo se asienta cierta representación idealizada respecto de lo que debe ser la dinámica democrática: un debate público y libre entre iguales en el que están representados todos los sectores e intereses en pugna en la sociedad. No obstante, la noción de representación parlamentaria se presenta como un dilema. Según Renata Hiller (2011), se trata de un sistema que "pretende abonar a la idea de soberanía popular, a la vez que constituye un mecanismo de selección de las voces reconocidas institucionalmente para expresarse y decidir sobre las cuestiones comunes". La misma autora se pregunta entonces "¿Solo puede llamarse democrático un sistema en el que participen todos? ¿Quiénes son esos todos? ¿Y cómo se representan? ¿Es inevitable algún modo de participación?" (2011: 171). En los debates parlamentarios se discuten proyectos de ley que poseen una estructura discursiva particular. El conjunto de artículos se encuentran acompañados de un texto justificatorio de la normativa propuesta. Allí se explicita cómo es entendido el asunto sobre el que versa y el modo en que afecta al interés público. Se trata de un texto polifónico, debido a que en el mismo pueden ser invocados una multiplicidad de discursos desde citas jurisprudenciales, doctrinas jurídicas, conceptos académicos, estadísticas, artículos periodísticos. El sentido de la política pública surge entonces del entretejido de una multiplicidad de discursos cuya circulación y reglas de formación son divergentes.

5 Competencia (dada por ser dictado por la autoridad correspondiente), causa, objeto, procedimiento (acorde al ordenamiento jurídico), motivación, finalidad, forma (Dec. №1.510/97). 
A los jueces se les asigna el deber de interpretar las leyes sancionadas por el Poder Legislativo. De no existir norma aplicable a un caso particular, los jueces tienen la capacidad de crear derecho sentando jurisprudencia en sus fallos. El término jurisprudencia refiere a aquellas sentencias en las que resuelven casos iguales o similares apelando a los mismos argumentos resolutivos. Siguiendo a Petracci y Pecheny "no obstante sea reiterada y uniforme, los jueces pueden apartarse de la jurisprudencia" (2007: 26), por lo tanto, tienen la potestad de fallar en forma diferente a la instituida aun cuando se trate de casos idénticos. Ello abre las puertas a la iterabilidad en la producción judicial. Con iterabilidad nos referimos al concepto elaborado por Derrida (1971) en torno a la imposibilidad de saturación última de sentido en la escritura. Para este autor, toda escritura refiere a "una marca que permanece, que no se agota en el presente de su inscripción y que puede dar lugar a una repetición en la ausencia" (1971: 11). De este modo, la repetición en contextos múltiples abre la posibilidad de alteración y apertura a la significación-otra, ya que esta nunca se encuentra plenamente cerrada. Es plausible identificar este mecanismo en la lógica judicial ya que al crear derecho a base de la interpretación de la ley, queda habilitada la apertura significante de la norma jurídica.

Cabe retomar los desarrollos realizados por Silvia Chejter (1990) quien aborda una serie de fallos judiciales para analizar el discurso jurídico sobre la violación ${ }^{6}$. La autora estudia los mecanismos y lógicas del ritual jurídico propios de los fallos judiciales. Según la autora, si bien estos encuentran su origen en hechos vividos por sujetos particulares, el evento jurídico se distancia de los sucesos tal como son vividos por los protagonistas. El hecho se (re)construye acorde a la liturgia procesal y los expedientes se conforman a partir de un relato polifónico en el que se alternan voces de distintos actores con registros, funciones y tiempos diversos: testimonios, peritajes, definiciones judiciales elaboradas por jueces, fiscales y abogados. La lógica de resolución de los casos es aquella que se ajusta al derecho. No obstante, dicha lógica se encuentra intrínsecamente en diálogo con el exterior. Tras cuestiones técnicas se encuentra un trasfondo social, ético, ideológico y político tanto en lo que refiere al marco social en el que es producido así como en lo que refiere a los intereses del magistrado que lo produce. Para la autora "no hay que olvidar que todo funcionario judicial está cursando una carrera con ascensos y promociones y busca el consenso de sus superiores" (1990: 114). La resolución final establecida por el juez para cada caso posee una estructura interna particular. En principio, se expone una recapitulación del suceso por parte del juez a partir de la totalidad de testimonios y peritajes. Luego se presentan las conclusiones que surgen del análisis de los mismos, sus relaciones internas leídas a la luz de los textos doctrinarios y normativos. Finalmente, según establece la autora "sobre esa elaboración autoritaria se emite una verdad incontestable e inapelable: el fallo" (1990: 15).

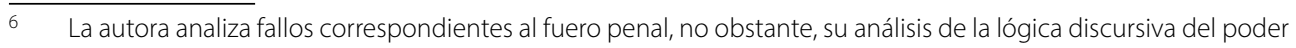
judicial puede ser aplicado al estudio de otros fueros. 


\section{Condiciones sociales de emergencia del derecho humano a la identidad de género}

Antes de adentrarnos en el análisis de contenido de los documentos seleccionados prestaremos atención a las condiciones históricas que habilitaron su emergencia. Consideramos que los cambios en la regulación de los cuerpos y las sexualidades es un fenómeno que debe ser entendido desde la óptica de la dinámica históricopolítica. En este sentido, es posible afirmar que el surgimiento de nuevos guiones regulativos responde a un paulatino proceso de consolidación de las organizaciones sexo-políticas ${ }^{7}$ a partir de la reapertura democrática (Pecheny, 2000; Meccia, 2006), así como a la correlación de fuerzas que se ha establecido entre las organizaciones de travestis, transexuales y transgéneros y ciertas áreas estatales en un momento determinado. Dichas agrupaciones iniciaron un proceso de organización y articulación de sus reivindicaciones frente al Estado a partir de la década del $1990^{8}$. Su consigna más notable giró en torno a la descriminalización de sus identidades ${ }^{9}$. Al mismo tiempo, apuntaron al cambio de los significantes por los cuales sus demandas eran otorgadas, particularmente aquellos que las asociaran a formas de vida enfermas o patológicas. Siguiendo a Josefina Fernández (2004), ALITT (Asociación de Lucha por la Identidad Travesti Transexual) fue la primera organización que planteó la cuestión de la identidad travesti como un tema central, realizando acciones tendientes a legitimar y reivindicar esta identidad. Debido a que el término "travesti"tiene su origen en el discurso médico y ha sido la categoría utilizada para criminalizar sus expresiones de género, la reivindicación del travestismo como identidad política requirió dotarla de nuevos contenidos.

Un hecho de marcada importancia en la incorporación de las demandas a la agenda estatal se dio en el año 2006 cuando la Corte Suprema de Justicia otorgó a ALITT el reconocimiento de su personería jurídica, tras haber sido rechazada la solicitud por parte de la Inspección General de Justicia (organismo oficial encargado de otorgarla). El reconocimiento público por parte del Estado a esta Asociación cuyos fines son "luchar para que el Estado y la sociedad acepten al travestismo como una identidad propia, lograr que las personas travestis y transexuales se conviertan en sujetas/os de derecho, lograr una mejor calidad de vida para las personas travestis

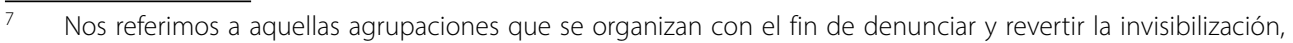
discriminación y estigmatización a la que distintos sujetos identificados como gays, lesbianas, bisexuales, travestis, transexuales o transgéneros -cuyas prácticas y deseos se distancian de la norma heterosexual dominante- se enfrentan cotidianamente.

8 Siguiendo a Josefina Fernández (2004), la primera organización del travestismo fue ATA (Asociación de Travestis Argentinas) creada en el año 1991. De la división al interior de dicha agrupación surgieron OTTRA (Organización de Travestis y Transexuales de Argentina) y ALITT (Asociación de Lucha por la Identidad Travesti Transexual). En la actualidad existen una multiplicidad de organizaciones trans. Algunas de ellas se incluyen bajo las identidades de travesti, transexual y/o transgéneros, femeninas y masculinas, mientras que otras nuclean en forma diferenciada identidades trans femeninas y masculinas.

$9 \quad$ La derogación de los Edictos Policiales en la ciudad de Buenos Aires en el año 1998 representó un hito en este sentido. Otras provincias cuyos Códigos de Convivencia criminalizaban el travestismo fueron lentamente eliminando dichos artículos. No obstante, hoy la gran mayoría de las provincias argentinas y la ciudad de Buenos Aires criminalizan la prostitución, hecho que redunda en la criminalización de las personas travestis, transexuales y transgéneros cuyo principal medio de supervivencia se encuentra constituido por dicha actividad. 
y transexuales" (AA.VV, 2008: 15), representó un momento bisagra en el modo de regular el travestismo, la transexualidad y la transgeneridad. Este pronunciamiento tuvo como antecedente el otorgamiento de personería jurídica a la CHA en 1991. En este caso la solicitud presentada en 1989 había sido negada tras la presunción de que los intereses de dicha organización no se correspondían con el "bien común". No obstante, luego de una serie de presiones ejercidas por la comunidad internacional, la Corte Suprema de Justicia se pronunció a favor en 1991 (Meccia, 2006). Siguiendo a Ernesto Meccia (2006), dicho fallo marcó un cambio respecto al modo sistemático de negación o relegación por parte del Estado de las demandas de los colectivos homosexuales en Argentina, en alineación a los intereses de la Iglesia Católica. Cabe tener en cuenta que la emergencia del virus del SIDA en la década de 1980 habilitó la apertura de la agenda pública internacional a la temática de la vulneración de derechos de las personas no heterosexuales (Pecheny, 2000). En el contexto local, el trabajo de las organizaciones sexo-políticas ante la enfermedad les permitió conformarse paulatinamente como interlocutores válidos frente al Estado ${ }^{10}$. Al mismo tiempo, las organizaciones lograron vincular la discriminación por orientación sexual con la problemática de los derechos humanos planteada enérgicamente después de la última dictadura militar. Todo ello, sumado al proceso de articulación con distintos actores sociales -como partidos políticos y organismos de derechos humanos-y la consecuente acumulación de capital social, configuró un marco propicio para dar el debate público respecto del estatus legal de las parejas del mismo sexo. Así fue posible la sanción en el año 2002 de la Ley de Unión Civil en el ámbito de la Ciudad de Buenos Aires y posteriormente la modificación de la Ley de Matrimonio Igualitario en el año 2010. Este proceso, focalizado en las demandas de los grupos gay-lésbicos redundó en una apertura estatal a las demandas de otros colectivos sexuales.

El contexto internacional también ha jugado un rol de peso en el proceso de incorporación de las demandas de los colectivos travestis, transexuales y transgénero a la agenda pública. En particular, la redacción de los "Principios de Yogyakarta sobre la Aplicación del Derecho Internacional de Derechos Humanos a las Cuestiones de Orientación Sexual e Identidad de Género" en el año 2006. Se trata de una serie de principios de derecho internacional en relación con la orientación sexual y la identidad de género con el fin de que tanto las Naciones Unidas como los Estados garanticen el respeto a los derechos humanos de las personas, independientemente de la orientación sexual $u$ identidad de género ${ }^{11}$. Estos principios se han ubicado como fundamento de peso para la elaboración de políticas públicas en esa dirección. A partir de dicha redacción se implementaron localmente una serie de acciones gubernamentales con el objeto de garantizar el respeto por la identidad de género autopercibida en distintas áreas del Estado'2.

10 Para profundizar sobre este punto se recomienda ver Pecheny (2000) y Bellucci (2010).

11 Para más información ver http: //www.oas.org/dil/esp/orientacion_sexual_Principios_de_Yogyakarta_2006.pdf

12 Entre ellas cabe hacer mención a la Resolución N².359/07 del Ministerio de Salud de la provincia de Buenos Aires, la Resolución N²272/07 del Ministerio de Salud del Gobierno de la Ciudad de Buenos Aires y la Ley N 3062/09 de la ciudad de Buenos Aires. 
Todos estos hechos trazaron una dinámica histórica en la que estos colectivos, como integrantes de un conjunto de organizaciones sexo-políticas, han logrado ubicarse como interlocutores válidos frente al Estado. El colectivo de travestis, transexuales y transgéneros comparte gran parte de las reivindicaciones de las organizaciones sexo-políticas locales, no obstante posee sus propias demandas específicas. Ello puede comprobarse al observar los datos expuestos en Cumbia, copeteo y lágrimas. Informe nacional sobre la situación de las travestis, transexuales y transgéneros (ALITT, 2007). Del mismo se desprende que asumir la identidad travesti es un proceso que en la gran mayoría de los casos se encuentra acompañado por experiencias de desarraigo familiar. La expulsión del espacio familiar y comunitario se extiende al ámbito educativo, generando la marginación escolar. Ello repercute las experiencias laborales y ubica a la prostitución como actividad casi exclusiva para la supervivencia material. A fin de revertir dicho estado de cosas, las organizaciones lograron promover una serie de regulaciones orientadas al reconocimiento y respeto de sus identidades por parte del Estado.

\section{LA IDENTIDAD DE GÉNERO COMO DERECHO HUMANO: ANÁLISIS DE TRES DOCUMENTOS}

El primer documento a analizar es una Resolución producida por la entonces Secretaría de Educación del Gobierno de la Ciudad de Buenos Aires en el año 2003. Se trata de un acto administrativo que recomienda a las instituciones educativas que "se garantice el respeto por la identidad de género, dignidad e integración de las personas pertenecientes a minorías sexuales" (Resolución N¹22/03). Si bien la idea de recomendación no parece implicar obligación por parte de dichas instituciones, se trata de un posicionamiento estatal que introduce una variación de importancia respecto de los vigentes hasta el momento. En principio, porque una instancia del poder ejecutivo se expide respecto de estas formas de vida que desafían el binarismo de género. Luego, porque lo establece a fin de que las propias percepciones genéricas sean respetadas por instituciones estatales.

El texto del acto administrativo da cuenta que el origen estuvo dado por un pedido particular realizado ante la Defensoría del Pueblo de la Ciudad de Buenos Aires, en el que se habría solicitado intervención de dicho organismo a fin de reconocer la identidad autopercibida de una persona en una institución educativa específica. De dicho pedido se desprendió la confección de una política pública que, al tiempo que comprenda dicha particular, establezca una política unificada para situaciones similares.

Cabe destacar algunos argumentos presentes en la fundamentación de dicha Resolución. En principio, la misma se orienta a garantizar el respeto por las libertades individuales. Luego, establece una tensión entre el deber del Estado de evitar cualquier tipo de discriminación y la necesidad de asegurar una identificación uniforme de todas las personas. Dicha tensión se resuelve afirmando que

"sin desconocer el principio de unidad, inmutabilidad y obligatoriedad del nombre, frente a la pretensión de declaración de identidad de la persona, debe primar una 
postura flexible que analice las dificultades concretas que ocasione la diferencia de nombre o apellido en cada caso" (Resolución N 122/03).

La idea de flexibilidad del ejercicio estatal es la que, según este posicionamiento, permite garantizar el respeto a los derechos humanos: "La universalidad de los derechos humanos debe expresarse en prácticas flexibles que aseguren su ejercicio por parte de sujetos muy diversos, ya que anteponer la rutina administrativa expulsaría a segmentos muy vulnerables del acceso a la ciudadanía plena" (Resolución N 122/03). Del texto se desprende que la violación a los derechos humanos se generaría al vedar el estatuto de ciudadanía plena de aquellas personas que no pueden transitar por las instituciones siendo reconocidas bajo su identidad autopercibida. La ciudadanía quedaría quebrantada por las consecuencias expulsivas que dicho irrespeto genera. Si bien este posicionamiento estatal asume que existe un aspecto identitario fundamental cristalizado en el nombre propio, también expone que se trata de un nombre propio que no es el oficialmente reconocido por el Estado. La balanza se inclina entonces hacia la flexibilidad en el ejercicio de lo público y la reinterpretación de las normas.

Resulta por lo menos paradojal el hecho que esta normativa de reconocimiento identitario, si bien sugiere que su origen estuvo dado por el reclamo de una persona travesti, no remite explícitamente en ningún momento a las nociones de travesti, transexual y/o transgénero. Por el contrario, refiere exclusivamente a la amplia e indiferenciada noción de "minoría sexual". Aun así, la apertura hacia una flexibilidad en las regulaciones representa el inicio de un proceso que tiene por objetivo generar un cambio en las lógicas estatales a fin de garantizar los derechos de aquellas presencias incómodas pero ineludibles.

El segundo documento seleccionado se trata de la Ley № 3.062, sancionada en el año 2009. Esta se propone "asegurar que travestis y transexuales sean nombradas ynombrados respetando su identidad de género" en toda dependencia pública de la Ciudad de Buenos Aires. La misma no solo incorpora la resolución recién comentada, sino que extiende la regulación a todas las dependencias estatales de dicha jurisdicción. Si bien comparte algunos sentidos expuestos en la anterior regulación, los profundiza y varía, exponiendo nuevos significados que ameritan su discusión.

A diferencia de la regulación anterior, esta normativa alude expresamente a las personas travestis, transexuales y transgéneros definiéndolas como "personas cuya identidad de género no se corresponde con el sexo que fuera consignado en su documento de identidad" (Ley N 3.062/09). Entiende que en términos colectivos son objeto de desventajas sistemáticas que impactan negativamente en sus condiciones de vida. Expresa que esa condición amerita la confección de políticas públicas específicas que reviertan dicha situación. De este modo, afirma que "para salvaguardar el derecho a la identidad de travestis y transexuales se requiere que los Estados adopten medidas que aseguren el respeto por la identidad de género que cada persona define para si" (Ley N 3.062/09).

En este pronunciamiento los derechos del colectivo se asegurarían no con flexibilidad, sino con medidas que garanticen el respeto por la identidad de género 
sostenida por ellas mismas. Retoma así la articulación entre identidad y participación ciudadana. Desde esta perspectiva, el respeto al nombre propio resulta una "medida imprescindible para asegurar su pleno desarrollo y su efectiva participación en la vida política, económica y social de la comunidad" (Ley N³.062/09). A partir de dicho respeto sería posible ampliar la órbita de derechos garantizados por el Estado hacia personas travestis y transexuales: "el derecho al trabajo, el derecho a la vivienda, el derecho a la cultura, entre otros" (Ley N³.062/09). Cabe decir que dicha ligazón entre respeto por el nombre propio y la garantía de acceso a otros derechos resulta hipotética, debido a que no refiere a la confección de políticas públicas que los concreten efectivamente.

En este posicionamiento el género es entendido como:

"Ia vivencia interna e individual del género tal como cada persona la siente profundamente, la cual podría corresponder o no con el sexo asignado al momento del nacimiento, incluyendo la vivencia personal del cuerpo y otras expresiones de género; incluyendo la vestimenta, el modo de hablary los modales" (Ley N³.062/09).

Dicha definición es tomada enteramente de los Principios de Yogyakarta sobre la Aplicación de la Legislación Internacional de Derechos Humanos en relación con la Orientación Sexual y la Identidad de Género ya mencionada. Concibe al género como un constructo sociocultural, por ende dinámico e histórico. Sobre la base de dicha idea, comprende al cuerpo como superficie transformable acorde al sentir de cada persona. Al mismo tiempo, entiende que siendo esta una dimensión profunda de la personalidad de las personas, debe librarse de cualquier tipo de imposición o juicio externo.

La normativa se ve fundamentada en tres pilares: el derecho a ser diferente, los derechos personalísimos y los derechos humanos. En lo que refiere al derecho a ser diferente, remite al artículo $N^{0} 11$ de la Constitución de la Ciudad de Buenos Aires ${ }^{13}$, interpretándolo en términos del "reconocimiento de la individualidad de cada ser humano, que puede expresar su identidad de diversas formas" (Ley No 3.062/09). Remite entonces a una noción de sujeto entendido bajo los términos del individuo liberal: indiviso, autoconsciente, autocentrado y cuyas fronteras identitarias -si bien pueden expresarse de diversas formas - resultan definidas de una vez y para siempre. Continúa fundamentándose apelando a la noción de derechos personalísimos, definidos como aquellas

"prerrogativas de contenido extrapatrimonial, inalienables, perpetuas y oponibles erga omnes, que corresponden a toda persona, por su sola condición de tal (...) e incluyen en esta categoría el derecho a la vida, a la integridad física, a la intimidad, a la propia imagen, a la inviolabilidad del domicilio, al honor, a la identidad y a la dignidad, entre otros (y que) lejos de construir un numerus clausus estos componentes están en continua evolución" (Ley N³.062/09).

13 El mismo establece que "Se reconoce y garantiza el derecho a ser diferente, no admitiéndose discriminaciones que tiendan a la segregación por razones o con pretexto de raza, etnia, género, orientación sexual, edad, religión, ideología, opinión, nacionalidad, caracteres físicos, condición psicofísica, social, económica o cualquier circunstancia que implique distinción, exclusión, restricción o menoscabo" (Constitución de la Ciudad Autónoma de Buenos Aires). 
Ahora bien, resulta oportuno preguntarse por los sentidos que encierra el estatus de persona: ¿Acaso lo que puede ser definido como persona no ha variado históricamente? ¿Acaso detrás de la noción de persona no se encuentra una idea de límite o frontera? Siguiendo a Roberto Espósito (2009), lo que se encuentra detrás de la noción de persona es "el umbral más allá del cual algo genéricamente viviente adquiere una significación que cambia en forma radical su estatus" (2009: 11). Dicho estatus es lo que le otorga a la vida biológica una investidura particular que la torna digna de respeto y valor. Es por ello que el autor afirma que "los derechos humanos no corresponden a los sujetos en cuanto ciudadanos sino únicamente en cuanto personas" (2009: 13). Es a partir del reconocimiento en tanto personas que pueden erigirse y hacerse efectivos los derechos de ciudadanía ${ }^{14}$. En este sentido, los derechos personalísimos se encuentran íntimamente ligados al último sustrato donde se fundamenta esta normativa: los tratados internacionales de derechos humanos. Allí se anuda la noción de identidad a la de dignidad de humana. De este modo, y basándonos en dichos tratados, la identidad debería ser resguardada más allá de las fronteras geográficas y de ciudadanía, siempre que se acceda previamente al estatus de persona.

Cabe entonces sostener que estas legislaciones que comienzan a circular en el 2003 se proponen incluir a las personas travestis, transexuales y transgéneros bajo la noción de persona, a fin de que las mismas dejan de estar incluidas en los cálculos del poder exclusivamente bajo la lógica de la biopolítica (Foucault, 1990) ${ }^{15}$. Es a partir de dicho sustrato que se las puede comenzar a pensar bajo el estatus de sujetos con derecho a tener derechos. No obstante, cabe preguntarse también por los mecanismos que instituyen nuevas fronteras al interior de la noción de persona. Esta normativa da cuenta de la existencia de sujetos que necesitan de un pronunciamiento estatal para acceder a personas con dicho estatus, a diferencia aquellas que prescinden de ello ya que, por el contrario, son siempre-ya-personas.

El último documento a analizar es un fallo producido en el 2010 por parte de un Juzgado en lo Contencioso, Administrativo y Tributario de la Ciudad de Buenos Aires (en adelante Fallo Scheibler). Se trata de un pedido de cambio de nombre y sexo registral

14 Siguiendo a Espósito (2009), el gran eje problemático que articula dicha tensión es el proceso que en las sociedades modernas ha llevado a la cosificación del cuerpo. Dicha cosificación se encuentra presente tanto en los esquemas biopolíticos como en el paradigma de los derechos humanos. No obstante la pretendida oposición entre regímenes bioanatomopolítico como fue el nazismo y las democracias modernas basadas en la presunta defensa de los derechos humanos, ambos esquemas de ciudadanía comparten la escisión cuerpo-razón, cuerpo-mente. En tanto seres humanos con una doble valencia racional-animal, solo adquieren estatus de personas quienes dominan plenamente la dimensión corporal bajo cierta definición normativa de lo humano, al tiempo que la posibilidad de ser plenos sujetos de derechos está dada siempre que se encarne dicha categoría.

15 Nos referimos al concepto foucaultiano de biopolítica que remite a las formas y en las cuales a partir del siglo XVII el ejercicio del poder comenzó a centrarse en el control de los procesos de la vida humana en tanto especie: "hacia mediados del siglo XVIII fue centrado en el cuerpo-especie, en el cuerpo transido por la mecánica de lo viviente y que sirve de soporte a los procesos biológicos: la proliferación, los nacimientos y la mortalidad, el nivel de salud, la duración de la vida y la longevidad, con todas las condiciones que pueden hacerlos variar; todos esos problemas los toma a su cargo una serie de intervenciones y controles reguladores: una biopolítica de la población" (Foucault, 1990: 131). 
de "masculino" a "femenino" de una persona que no presenta ni solicita la realización de una cirugía de reasignación genital.

Acorde a la mecánica judicial a la que hemos referido previamente, en este fallo el juez expone el caso tal como el mismo le fue presentado. Allí se incluye un relato de vida en el que la solicitante manifiesta que "desde muy temprana edad sintió un deseo irrefrenable de vestirse y relacionarse conforme el sexo femenino" (Fallo Scheibler). El juez afirma la importancia para el orden público de la inmutabilidad del nombre. No obstante, explicita que existe mecanismo legal de modificarlo acorde a la Ley del Nombre, no siendo este el caso para el cambio de sexo registral. Destaca que en los casos en los que este tipo de pedidos han sido autorizados judicialmente se contó siempre con el requisito de la cirugía de reasignación genital. A fin de evaluar lo solicitado, establece diferencias conceptuales entre la noción de sexo respecto de la de género, explicitando que "se entiende por'género' al conjunto de pautas culturales y sociales que se utilizan para distinguir las actitudes o conductas que socialmente se consideran masculinas o femeninas" (Fallo Scheibler). Luego establece que

"Tradicionalmente, el sexo de una persona es fijado en el momento de su nacimiento, circunstancia que determina su registro dentro de las categorías convencionales de 'hombre'y 'mujer.' Sin embargo, ocurre que este hecho puede resultar altamente conflictivo para un porcentaje de individuos. Este grupo está compuesto (...) por personas cuya autopercepción innata difiere de la percepción que su entorno tiene de ellas y en base a la cual se las registró al momento de su nacimiento" (Fallo Scheibler).

Cabe mencionar este pasaje en particular debido a que aquí el juez no recurre a categorías médicas ni tampoco reduce el problema a un caso aislado, lo que lo diferencia radicalmente respecto de los fallos emitidos hasta dicho momento. Por el contrario, lo entiende como una experiencia común a un grupo de personas y que nada determina necesariamente la identidad de género que los sujetos habrán de adoptar. Reconoce que estas múltiples posibilidades identificatorias no tienen posibilidad de ser formalmente reconocidas por los mecanismos estatales vigentes. En esa misma línea argumental sostiene que las mismas "no constituyen 'perversiones,' 'desviaciones,' 'sujetos sexualmente inclasificables' o 'errores de la naturaleza'.' Se establece entonces una disrupción respecto de los guiones regulativos vigentes en el ámbito judicial en torno al travestismo, transexualidad y transgeneridad. Afirma, por el contrario, una noción pluralista y no patologizante respecto de las identidades genéricas que escapan del binarismo genérico.

Si bien en este caso no se recurre a pericias médicas ni establece como requisito la cirugía de reasignación genital, sí se establece como condición la estabilidad, persistencia y reconocimiento por parte de los otros del género que se pretende validar legalmente. Una existencia acorde a los patrones sociales del género reclamado, en condiciones estables y contando con la posibilidad de acreditar dicha estabilidad por parte de otras personas, son las condiciones impuestas en este caso para obtener el reconocimiento estatal. Poseen entonces valor de pruebas jurídicas las declaraciones de los/as testigos presentados por la solicitante quienes afirmaron que 
"desde que conocen a la actora siempre la han visto con aspecto y comportamiento femenino (y) destacaron los múltiples inconvenientes y padecimientos que le produce la circunstancia de no poder contar con documentación que refleje su identidad de género y el nombre femenino por el que es conocida y con el cual interactúa en sociedad" (Fallo Scheibler).

Es así que el juez puede afirmar que "la actora posee una identidad femenina, que exterioriza en su aspecto y en el nombre por el que es conocida e interactúa socialmente (...) y que tal circunstancia se presenta de modo establey persistente" (Fallo Scheibler). Su "identidad femenina", entonces, es corroborada por el juez, aun sin establecer cuáles son los contenidos o las condiciones que permiten establecer dicha afirmación, ya que ello le haría incurrir en los mismos estereotipos de los cuales busca desprenderse. Su resolución se basa en la protección del principio de autonomía personal y la valoración de los propios planes de vida, absteniéndose de considerarla como una persona cuya existencia deba ser tutelada.

La exposición argumental se encuentra atravesada por una tensión entre el interés individual y el colectivo. No obstante, se considera que en este caso el interés individual se encuentra incluido en el interés colectivo, porque ello tendería a promover la inclusión social de la totalidad de los integrantes del colectivo social más allá de la diversidad de deseos y corporalidades que estos posean. Cabe retomar aquí a Leticia Sabsay (2011), para quien la protección y celebración de la diversidad por la diversidad misma, "se limita a clasificar una cantidad de identidades discretas (...) cooptadas por una idea implícita de universalidad que clausura la 'diferencia' y la limita a lo que esa noción universal de 'diversidad' prevé como aceptable" (2011: 75). De este modo, el reconocimiento otorgado bajo la bandera de la protección de la diversidad, corre el riesgo de dejar fuera de discusión los mecanismos que hacen que algunas identidades tengan que llegar a la instancia de solicitarle al Estado que las reconozca como humanas mientras que otras son definidas como tales de por sí.

El fallo reconoce la identidad como parte del fuero íntimo, privado y personal. Esta noción se basa no solo en la división liberal de lo público y lo privado, sino que también se sustenta en una idea de sujeto que al decir de Sabsay, debe ser "capaz de realizar demandas de derechos sobre la base del establecimiento de fronteras que estabilizan su identidad" (2011: : 78). Es un sujeto que para devenir sujeto de derecho -y antes que ello, persona- precisa ser autónomo, autoconsciente y autocentrado con una identidad estable. Estas concepciones dejan de lado el hecho de que las nociones de autonomía o autoproducción conllevan un dilema, ya que no es posible pensar un sujeto que tome sus decisiones escindido de los marcos históricos de relaciones de poder-saber que lo producen como tal. Cabe entonces preguntarse si el hecho de vivir en cierto modo acorde al género masculino o femenino, en ninguno de ellos, o en una permanente transición entre ambos, responde a una decisión independiente y voluntaria de cualquier persona, o si más bien demuestra la imposibilidad de encarnar plenamente los géneros en términos binarios y lineales. De la lectura de este fallo cabe pensar que el requisito jurídico para ser cifradas como identidades posibles sigue siendo la correcta encarnación de los géneros hegemónicamente instituidos. 


\section{REFLEXIONES FINALES}

En el presente trabajo nos propusimos abordar los sentidos que cristalizan en distintos documentos oficiales en los que se concibe el respeto a la identidad de género y los deseos de travestis, transexuales y transgéneros como un derecho humano.

Se comenzó analizando la relación entre discurso jurídico y orden social, considerando que el discurso jurídico opera como dispositivo de legitimación y sostén del reparto desigual del poder ofreciendo los mecanismos de obediencia y control social necesarios para la reproducción de un orden social jerárquicamente organizado. Es un discurso que posee la capacidad de interpelar la emotividad de los sujetos, movilizar sus creencias y sentimientos, así como nombrarlos y especificarlos mediante las categorías que ofrece. El discurso jurídico es también un lenguaje en disputa por su doble valencia de locus de discurso legitimado y de legitimación. Se consideró necesario entonces reflexionar sobre la forma en la que este discurso configura y regula las corporalidades en términos genéricos, ya que el mismo funciona como un ámbito en el que se disputa la definición de la frontera culturalmente establecida entre los cuerpos legítimos y los ilegítimos y los límites de aquello que puede definirse como humano.

A partir del análisis de los tres documentos seleccionados surgieron una serie de nociones que vale la pena destacar. El primer documento analizado se trató de una resolución producida por la entonces Secretaría de Educación del Gobierno de la Ciudad de Buenos Aires en el 2003. Allí se recomienda que las instituciones educativas garanticen el respeto por la identidad de género de las personas pertenecientes a minorías sexuales. Dicha normativa expone como fundamento el respeto por las libertades individuales. Sostiene que el ejercicio pleno de la ciudadanía queda quebrantado por las consecuencias expulsivas del no reconocimiento a la identidad de género autopercibido en las instituciones educativas. En la misma se tensiona de un modo particular el deber del Estado de evitar cualquier tipo de discriminación y la necesidad de garantizar una identificación uniforme de todas las personas. La idea de flexibilidad en el ejercicio estatal es la que en este posicionamiento permite garantizar el respeto a los derechos humanos de las minorías sexuales. Cabe destacar que dicha norma no establece una referencia explícita a las nociones de travestismo, transexualidad y/o transgeneridad.

El segundo documento analizado, la Ley $N^{\circ} 3.062$, dispone "asegurar que travestis y transexuales sean nombradas y nombrados respetando su identidad de género" en toda dependencia pública de la Ciudad de Buenos Aires. De este modo hace explícita referencia a travestis y transexuales y expone que los derechos de este colectivo se aseguran, no con flexibilidad, sino con medidas que garanticen el respeto por la identidad de género sostenida por ellas mismas. Esto es, la confección de políticas públicas específicas. En este pronunciamiento se presenta una noción de género entendido como un constructo sociocultural, dinámico e histórico, en el que el cuerpo es superficie transformable acorde al sentir de cada persona. Al mismo tiempo, entiende que siendo esta una dimensión profunda de la personalidad de las personas, debe librarse de cualquier tipo de imposición o juicio externo. La normativa se ve fundamentada 
en tres pilares: el derecho a ser diferente, los derechos personalísimos y los derechos humanos. Del abordaje de la noción de los derechos personalísimos se desprende que es a partir del reconocimiento primario como personas que pueden erigirse y hacerse efectivos los derechos de ciudadanía y los derechos humanos.

El tercer documento refiere a un fallo producido por un Juzgado en lo Contencioso Administrativo de la Ciudad de Buenos Aires el 2010. Allí se autoriza el cambio de nombre y sexo registral de una persona que, habiendo sido registrada al momento de nacer como perteneciente al sexo masculino, desea ser reconocida legalmente como femenina. El juez no recurre a categorías médicas ni tampoco reduce el problema a un caso aislado. Por el contrario, lo entiende como una experiencia común a un grupo de personas. En esa misma línea argumental sostiene que no constituyen perversiones ni desviaciones. No obstante sí establece como condición para la evaluación positiva del pedido la persistencia y reconocimiento por parte de los otros del género que se pretende validar legalmente. Su resolución se basa en la protección del principio de autonomía personal y la valoración de los propios planes de vida, absteniéndose de considerarla como una persona enferma cuya existencia deba ser tutelada. Allí la noción de sujeto es entendida en los términos del individuo liberal, cuyas fronteras identitarias -si bien pueden expresarse de diversas formas- resultan definidas de una vez y para siempre. Es un sujeto que para devenir sujeto de derecho precisa ser autónomo, autoconsciente y autocentrado con una identidad estable. Ello se ve reflejado en el requisito de la estabilidad y persistencia en el género autoatribuido. Se resaltó entonces que dichas concepciones dejarían de lado el hecho de que las nociones de autonomía o autoproducción conllevan un dilema, ya que no es posible pensar un sujeto que tome sus decisiones escindido de los marcos históricos de relaciones de poder-saber que lo producen como tal.

El contenido de estos documentos da cuenta que las demandas de los colectivos travestis, transexuales y transgéneros son incorporadas por las agencias estatales bajo sentidos no necesariamente homogéneos. Su ingreso se desarrolla en medio de tensiones caras al ámbito jurídico, esto es, entre la garantía de los derechos individuales y la garantía de los derechos colectivos; entre la flexibilidad en el ejercicio de lo público y la confección de políticas públicas específicas. Al mismo tiempo, si bien la noción de género busca utilizarse en términos desbiologizados, mantiene un sentido binario y posee un contenido marcadamente normativo. Por último, la existencia de estos documentos da cuenta que el acceso al estatus jurídico de persona se erige como condición primera e ineludible para el posterior ingreso a la ciudadanía como sujeto pleno de derecho. Resulta necesario entonces seguir abordando críticamente los sentidos que los mismos encierran a fin de impedir la reificación de nociones como sexo y género, pero por sobre todo, del intrincado concepto de lo humano.

\section{BIBLIOGRAFÍA}

AA.W. (2008): Políticas de reconocimiento. Buenos Aires: Ediciones Ají de pollo.

ALITT (2007): Cumbia, copeteo y lágrimas. Informe nacional sobre la situación de las travestis, transexuales y transgéneros, Buenos Aires: ALITT. 
Austin, John (1988). Cómo hacer las cosas con palabras. Palabras y acciones. Barcelona: Paidós.

Bellucci, Mabel (2010): Orgullo. Carlos Jáuregui, una biografía política. Buenos Aires: Emecé.

Bento, Berenice (2006a): A reinvenção do corpo: sexualidade e gênero na experiência transexual. Garamond: Rio de Janeiro.

Berkins, Lohana (2003): "Un itinerario político del travestismo", en Maffía, D. (comp.): Sexualidades Migrantes. Género y Transgénero, pp. 127-137. Buenos Aires: Feminaria.

Billings, Dwight y Urban, Thomas (1998): "La construcción sociomédica de la transexualidad: interpretación y crítica", en: José Antonio Nieto (comp.): Transexualidad, transgenerismo y cultura. Antropología, identidad y género, pp. 91-121. Madrid:Talasa.

Butler, Judith (2006a): “Desdiagnosticar el género”, en Deshacer el género, pp. 113-149. Barcelona: Paidós.

(2006b): Vida precaria. El poder del duelo y la violencia. Buenos Aires: Paidós.

- (2001a): El género en disputa, Barcelona, Paidós.

- (2001b): Mecanismos psíquicos del poder. Teorías sobre la sujeción. Madrid: Ediciones Cátedra.

Cabral, Mauro (2008): Comparecer. Un comentario. [on line]. Disponible en: http: //www. artemisanoticias.com.ar/site/notas.asp?id=51\&idnota=6287. [Recuperado el $17 \mathrm{de}$ abril de 2012].

De Lauretis, Teresa (1998): "La tecnología del género", en Revista Mora N 4, Instituto Interdisciplinario de Estudios de Género, octubre 1998.

Derrida, Jaques (1971): Firma, acontecimiento, contexto [on line]. Disponible en http: //www. ddooss.org/articulos/textos/derrida_firma.pdf [Recuperado el 17 de abril de 2012].

(1992): "Fuerza de ley: el fundamento místico de la autoridad", en Revista Doxa. 11, 129-191.

Dollar, Mladen (2007):"La política de la voz", en Una vozy nada más, pp. 129-151. Buenos Aires: Manantial.

Entelman, Ricardo (1982): "Aportes a la formación de una epistemología jurídica en base a algunos análisis del funcionamiento del discurso", en WAA. El discurso jurídico. Perspectiva psicoanalítica y otros abordajes epistemológicos, pp. 85-109. Buenos Aires: Hachette. 
Espósito, Roberto (2009): Tercera persona. Política de la vida y filosofía de lo impersonal. Buenos Aires: Amorrortu.

Farji Neer, Anahí (2012): "Producción generizada de los cuerpos en el discurso jurídico argentino. Análisis de tres fallos correspondientes al período 1970-2010", en Revista Sociedad y Equidad, N³, enero 2012, pp. 1-22.

Fernández, Josefina (2004): Cuerpos desobedientes. Travestismo e identidad de género, Buenos Aires: Edhasa.

Foucault, Michel (2009): La verdad y las formas jurídicas. Barcelona: Gedisa.

(2000): Los anormales. Buenos Aires: Fondo de Cultura Económica.

- (1997): Arqueología del Saber. México: Siglo XXI Editores.

(1990): Historia de la sexualidad. Buenos Aires: Siglo XXI Editores.

(1987): El orden del discurso. Barcelona: Tusquets.

Hiller, Renata (2011): "Parlamentos, tensiones en torno a la representación sobre el matrimonio gay-lésbico", en Gutiérrez, María Alicia (Comp.) Voces polifónicas. Itinerarios de los géneros y las sexualidades, pp. 167-199. Buenos Aires: Ediciones Godot.

King, David (1998): "Confusiones de género: concepciones psicológicas y psiquiátricas sobre el travestismo y la transexualidad", en: José Antonio Nieto (comp.) Transexualidad, transgenerismo y cultura. Antropología, identidad y género (pp. 123.157). Madrid:Talasa.

Laclau, Ernesto. y Mouffe Chantal (2004): Hegemonía y estrategia socialista. Buenos Aires: Fondo de Cultura Económica.

Leite, Jorge (2008): Nossos corpos também mudam. Sexo, gênero e a invenção das categorias "travesti" e "transexual" no discurso científico. Tesis de Doctorado no publicada, Pontifícia Universidade Católica de São Paulo, Doutorado em ciências sociais, Brasil.

Maffía, Diana (2001):"Ciudadanía sexual. Aspectos personales, legales y políticos de los derechos reproductivos como derechos humanos", en Revista Feminaria Año XIV, pp. 26-30.

Marí, Enrique (2002): La Teoría de las Ficciones. Buenos Aires: Eudeba.

- (1996): Papeles de filosofía 2 (... para arrojar al alba): La teoría de las ficciones en la política y la filosofía. Buenos Aires: Biblos.

(1994): Derecho y psicoanálisis. Teoría de las ficciones y ficción dogmática. Buenos Aires: Edicial. 
(1986): "Racionalidad e imaginario social en el discurso del orden", en Revista Doxa. Cuadernos de Filosofía del Derecho. 3, pp. 93-112.

Meccia, Ernesto (2006): La cuestión gay. Un enfoque sociológico, Buenos Aires: Gran Aldea Editores.

Moreno, María Aluminé (2001): "Políticas sociales, ciudadanía y corporalidad: vínculos y tensiones", en Revista Feminaria. 28/29, pp. 16-24.

Oszlak, Oscar y Guillermo O’ Donnell (1984): “Estado y políticas estatales en América Latina. Hacia una estrategia de investigación", en Kliksberg, Bernardo y José Sulbrandt (Comps.): Para investigar la administración pública, Madrid: INAP.

Oszlak, Oscar (1978): Formación histórica del Estado en América Latina: elementos teóricometodológicos para su estudio. Buenos Aires: CEDES.

Pateman, Carole (1995): El contrato sexual. Barcelona: Anthropos/Universidad Autónoma Metropolitana.

Pecheny, Mario (2000):"La salud como vector del reconocimiento de derechos humanos: la epidemia de SIDA y el reconocimiento de los derechos de las minorías sexuales, en Ana Domínguez Mon et al. La salud en crisis. Un análisis desde la perspectiva de las ciencias sociales, pp. 199-215. Buenos Aires: Ed. Dunken.

Petracci, Mónica y Mario Pecheny (2007): Argentina, derechos humanos y sexualidad, Buenos Aires: Cedes.

Rubin, Gayle (1989): "Reflexionando sobre el sexo: notas para una teoría radical de la sexualidad", en Vance, C. (comp.) Placery peligro. Explorando la sexualidad femenina. Madrid: Editorial Revolución.

Sabsay, Leticia (2011): Fronteras sexuales: espacio urbano, cuerpos y ciudadanía. Buenos Aires: Paidós.

Segato, Rita (2003): Las estructuras elementales de la violencia. Ensayos sobre género entre la antropología, el psicoanálisis y los derechos humanos. Buenos Aires: Prometeo.

Valentine, David (2007): Imagining transgender. An Ethnography of a category. London: Duke University Press.

\section{DOCUMENTOS}

Constitución de la Ciudad de Buenos Aires.

Decreto № 1.510/97, Boletín Oficial №310/97, GCBA, octubre 27, 1997. 
Resolución Nº 122/03, Boletín Oficial Nº 1.642/03, GCBA, marzo 3, 2003.

Ley N³.062/2009, Boletín Oficial N³.200/2009, junio 23, 2009.

"Fallo Scheibler": Juzgado 1 ra Instancia en lo Contencioso Administrativo y Tributario de la Ciudad Autónoma de Buenos Aires: "D. A. C/GCBA S/ AMPARO (ART. 14 CCABA) (Expte. No EXP 39.475/0)"; Sentencia 29 de diciembre de 2010. 
